\title{
Synthesis of Graphene Oxide Enhanced Agar Composites: A Biocompatible Photo-catalyst for Degradation of Organic Dyes
}

\author{
Shreyas Dindorkar*a, Jaymin Mistry ${ }^{a}$, Jayesh Hire ${ }^{a}$, Khushi Jain ${ }^{b}$, Nandini Khona ${ }^{b}$, Shreya Peddakolmi ${ }^{b}$ \& Paresh More ${ }^{a b}$ \\ a Department of Chemistry, K. E. T's, Vinayak Ganesh Vare College (Autonomous), Mulund, Mumbai, India \\ ${ }^{b}$ Department of Biotechnology, K. E. T's, Vinayak Ganesh Vaze College (Autonomous), Mulund, Mumbai, India
}

bttps:/ / doi.org/10.33697/ajur.2020.025

Students:shreyasdindorkar@gmail.com*,jayminmistry2000@gmail.com,jayesh.bire456@gmail.com,jainkhushi2812@gmail.com, k.hona.nandini1805@gmail.com,peddakolmis@gmail.com

Mentor:paresh.m34@gmail.com

\begin{abstract}
Herein we report the synthesis of graphene oxide-based agar composites using a solution casting method. Graphene oxide was synthesized by modified Hummer's method and was characterized using X-ray diffraction (XRD) and Raman spectroscopy. The graphene oxide-based agar composites were characterized using X-ray diffraction (XRD) and UV-visible spectroscopy. Optical band gap obtained from the Tauc plot showed that the composites could be used in the photodegradation of dyes. The synthesized composite material was checked for its practical applicability in the degradation of methylene blue dye under solar irradiation; with an increase in the concentration of graphene oxide, catalyst, and $\mathrm{H}_{2} \mathrm{O}_{2}$, the rate constant increases. The rate constant was found to be inversely proportional to the concentration of methylene blue dye. Dosage of graphene oxide was found to be the most prominent factor in increasing the rate of photodegradation. It is clear from the data for the reaction system that the degradation reaction follows pseudo-first-order kinetics.
\end{abstract}

\section{KEYWORDS}

Composites; Ultra-sonication; Photodegradation; Methylene Blue; XRD; Graphene Oxide; Kinetics; Biocompatibility

\section{INTRODUCTION}

Dyes are an important class of synthetic organic compounds used in many industries, especially textiles. Consequently, they have become common industrial environmental pollutants during their synthesis and later during fiber dyeing. ${ }^{1}$ The harmful organic substances generated from chemical, textile, and dye industries are highly polluting the water resources and producing serious problems to all life and their environment. Organic dyes are toxic, mutagenic, and carcinogenic. ${ }^{2}$ Around $10-20 \%$ of the dyes are lost during the dyeing process, and hence, the removal of textile dyes from contaminated water bodies has become a concern worldwide. ${ }^{3}$ The natural photosynthesis cycle process is also affected by the discharge of the textile industry effluents into the environment. ${ }^{4}$ If allowed to flow in drains and rivers, it affects the quality of drinking water in hand pumps, rivers, lakes, and potable reservoirs, making them unfit for human consumption. It is important to remove these pollutants from the wastewaters before their final disposal. Hence, there is a need to address the pollution problem immediately. Due to the chemical and biological stability, the removal of the toxic dyes by natural degradation processes is difficult. ${ }^{5-8}$ The effective removal of these dyes before discharge or their conversion into useful or less harmful products is of great importance. Various attempts are being made worldwide to address this issue by synthesizing novel materials for degradation or conversion of dyes into less harmful products. However, many of these materials, such as $\mathrm{TiO}_{2}$, are toxic to living communities. Replacement of such materials with biodegradable or biocompatible ones is the most attractive yet simple strategy and has received much attention in the last few years. ${ }^{9-11}$

Graphene oxide (GO), a derivative of graphene, is in use for about one and a half centuries. It is a two dimensional (2-D) covalently bonded and oxygen-rich carbon skeletal. Because of its large surface area, excellent strength, and reactive oxygenated groups spread over its surface, it has recently attracted attention in various fields such as optoelectronics, energy storage, catalysis, thermoelectric devices, tissue engineering, and drug delivery. ${ }^{12-16}$ The functionalized surface of graphene oxide with reactive oxygenated species distinguishes it from graphene and has attracted scientists towards its valuable applications in chemistry (Figure 1). This oxygen-rich nature of graphene oxide is responsible for its easy dispersibility in water. This is the most important property of graphene oxide as it enables one to dope it into the polymer and ceramic matrices. Moreover, it also shows excellent dispersibility in most of the organic solvents such as $\mathrm{N}$, N-dimethylformamide. ${ }^{17}$ Hence, graphene oxide is used in the wet preparation experiments in both aqueous media as well as in organic media. The electrical, mechanical, catalytic properties of 
ceramics, polymers, and composites can be enhanced by doping them with graphene oxide. It was also found that the mechanical strength, electrical conductivity of polymers, more specifically ceramics, were increased to many folds when doped with graphene oxide. ${ }^{18-19}$ Graphene oxide is non-toxic at low concentrations, and the toxicity can be further reduced by surface modification with biocompatible material. ${ }^{20}$

Biodegradable polymers have expanded the idea to tackle the growing environmental problem associated with the use of synthetic polymers leading to plastic waste. The hunt for cost-effective, environmentally friendly materials has led to the development of different biodegradable plastics. ${ }^{21}$ Agar is a jelly-like substance obtained from red marine algae and possesses distinctive characteristics such as biocompatibility, solubility in water, biodegradability, and low cost. It gets its gelling properties from an unbranched polysaccharide, which is obtained from the cell walls of some species of red algae, primarily from Gelidiaceae and Gracilaria. It has a wide range of applications, most commonly in the pharmaceutical and medical industries. ${ }^{22}$

There are numerous reports in the literature where graphene oxide has been combined with other materials to make nanocomposites for application in the degradation of industrial dyes. M. Bakhtir Azim et al. synthesized GO-TiO 2 nanocomposites for degradation of methylene blue (MB), which showed around 89\% degradation. ${ }^{23}$ Humaira Seema et al. had reported the synthesis of $\mathrm{GO}-\mathrm{SnO}_{2}$ composites which gave complete degradation of methylene blue under solar light. ${ }^{24} \mathrm{Yanhui}$ Li et al. synthesized GO-Agar aerogel for removal of methylene blue dye, which exhibited an excellent adsorption capacity of 578 $\mathrm{mg} / \mathrm{g}$ and reusability up to 3 cycles. ${ }^{25}$ Gelatin/PVA-GO biocomposites have been reported by L. E. Crica et al., which showed remarkable improvements in mechanical properties. ${ }^{26}$

Methylene blue is an industrial dye that is commonly used for dying fabrics and in staining biological samples. Apart from industries, it finds application as medication. It is mainly used to treat methemoglobinemia and methemoglobin levels that are greater than $30 \%$. However, if present in high concentrations, it is extremely hazardous to human health. Direct contact of methylene blue with eyes causes extreme irritation, and it is highly toxic by oral and intravenous routes. It is also combustible in powder form and releases highly toxic gases such as nitrogen oxides. Therefore, proper treatment is necessary before releasing such dyes into water bodies.

Verma et al. and their group have reported biocompatible graphene and graphene oxide doped agar composites, which exhibited excellent tensile strength, thermal properties, and water resistance property. ${ }^{27}$ The present work is on the same line as Verma et al. and aims to synthesize biocompatible Agar@GO composites by a simple solution casting method. Various analytical techniques such as XRD, Raman, UV-Visible were utilized. Further, the composites were tested for photocatalytic degradation of methylene blue.

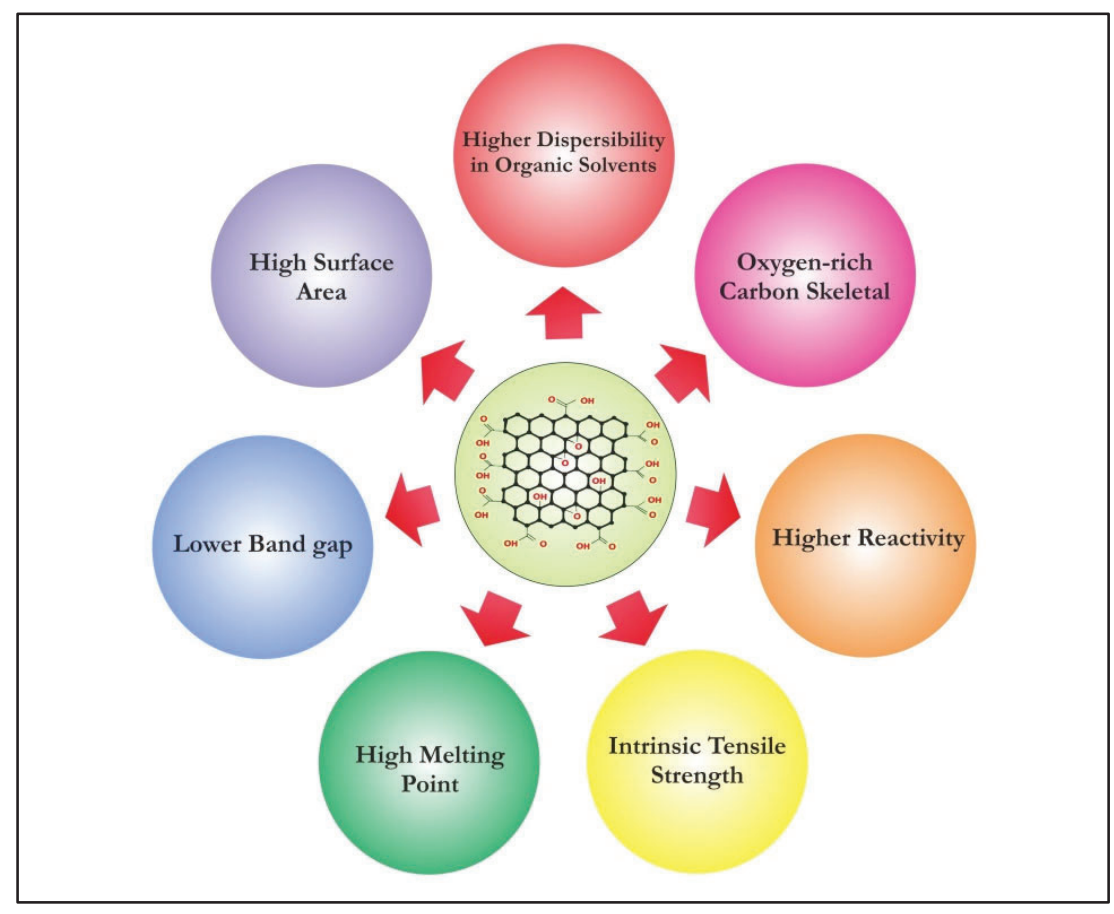

Figure 1. Properties of graphene oxide. 


\section{EXPERIMENTAL}

\section{Materials:}

Finely powdered graphite was purchased from LOBA Pvt. Ltd. Gelatin Agar powder was purchased from Weiss mill. Potassium permanganate $\left(\mathrm{KMnO}_{4}\right)$, sulfuric acid $\left(\mathrm{H}_{2} \mathrm{SO}_{4}, 98 \%\right)$, hydrochloric acid $(\mathrm{HCl}, 10 \%)$, hydrogen peroxide $\left(\mathrm{H}_{2} \mathrm{O}_{2}, 30 \%\right)$, sodium nitrate $\left(\mathrm{NaNO}_{3}\right)$ were of the analytical grade and were used as received.

\section{Synthesis of Graphene oxide:}

Graphene oxide was synthesized by modified Hummer's method. ${ }^{28} 2.0 \mathrm{~g}$ of finely powdered graphite and $1.0 \mathrm{~g}$ of sodium nitrate $\left(\mathrm{NaNO}_{3}\right)$ were added to $\mathrm{H}_{2} \mathrm{SO}_{4}(46 \mathrm{ml} ; 98 \%)$. The mixture was subjected to constant stirring for 1 hour. $6.0 \mathrm{~g}$ of analytical grade $\mathrm{KMnO}_{4}$ was then added gradually to the mixture. The temperature of the reaction system was maintained at $20^{\circ} \mathrm{C}$ using an ice bath. After addition, the mixture was stirred constantly for 12 hours at $35^{\circ} \mathrm{C}$ using a magnetic stirrer. The solution thus obtained was diluted with $500 \mathrm{ml}$ distilled water under constant stirring. Dilution was followed by the addition of $5.00 \mathrm{ml} \mathrm{H}_{2} \mathrm{O}_{2}(30 \%)$. The resulting product was washed with distilled water to remove the traces of acid, followed by washing with absolute alcohol. The product was dried at $60^{\circ} \mathrm{C}$ for 2 hours and stored in a vial for further experiments.

\section{Synthesis of Agar@GO composites:}

Agar@GO composites were synthesized by a simple solution casting method.20 To prepare 5\% (w/w) Agar@GO composites, 5.0 $\mathrm{mg}$ of graphene oxide powder were dispersed in 10\% absolute alcohol and subjected to ultra-sonication for 30 min. Agar solution was prepared by dissolving $100.0 \mathrm{mg}$ of agar powder in distilled water at $60^{\circ} \mathrm{C}$ followed by ultrasonication for $30 \mathrm{~min}$. Both the solutions were then mixed and ultra-sonicated at $60^{\circ} \mathrm{C}$ for $60 \mathrm{~min}$. The adduct so formed was then allowed to cool down at room temperature to obtain jelly-like material, which was air-dried and pulverized to obtain the composites. Similarly, composites with $10 \%, 20 \%$, and $25 \%$ of graphene oxide (w/w) were synthesized and studied for further applications.

\section{Characterization:}

The structural properties of the synthesized graphene oxide and Agar@GO composites were investigated by X-ray diffraction (XRD) technique at room temperature with Xpert pro MPD X-ray diffractometer with $\mathrm{Cu}-\mathrm{K} \alpha$ radiation $(\lambda-1.5405 \AA$ ) . Diffraction patterns were recorded at a scan speed of $0.3^{\circ}$ at $40 \mathrm{KV} / 30 \mathrm{~mA}$. Raman spectroscopy was carried out using RENISHAW micro Raman system with power $5 \mathrm{Mw}$ to confirm the formation of graphene oxide. The optical properties of composites and photodegradation of methylene blue dye were studied using a UV-visible spectrophotometer (Shimadzu 1800) with a scanning interval of $0.5 \mathrm{~nm}$ from $200 \mathrm{~nm}$ to $800 \mathrm{~nm}$.

\section{Photodegradation Experiment:}

A simple photodegradation experiment was carried out for the degradation of methylene blue dye under sunlight to investigate the photocatalytic activity of composites. $100 \mathrm{ppm}$ stock solution of the dye was prepared by dissolving $0.1 \mathrm{~g}$ of methylene blue (molecular weight $-319.85 \mathrm{~g} / \mathrm{mol}$ ) in $1000 \mathrm{ml}$ of distilled water. $50.00 \mathrm{ml} 20 \mathrm{ppm}$ solution of dye was then prepared using the stock solution. To the $50.00 \mathrm{ml}$ of the above dye solution, the desired amounts of Agar@GO composites were added, followed by the addition of oxidizing agent $\mathrm{H}_{2} \mathrm{O}_{2}$. The mixture was then exposed to irradiation with occasional stirring. Aliquots of the irradiating mixture were taken at a constant interval of $10 \mathrm{~min}$ and were analyzed by a UV-visible spectrophotometer. The effect of various reaction parameters vi: amount of Agar@GO composites, the concentration of the dye solution, and the amount of $\mathrm{H}_{2} \mathrm{O}_{2}$ was investigated.

\section{RESULTS}

1. X-ray Diffraction and Raman Spectroscopy:

The X-ray diffractogram of chemically synthesized graphene oxide is shown in Figure 2a. Along with an intense peak around $2 \theta$ $=10^{\circ}$, a small hump appeared at $2 \theta=43 \cdot 1^{\circ}$. No peak was observed around $2 \theta=26^{\circ}$, which indicates the complete conversion of graphite into graphene oxide. ${ }^{29}$ The Raman spectra recorded for graphene oxide (Figure 2b) shows two bands at $1349 \mathrm{~cm}^{-1}$ and $1599 \mathrm{~cm}^{-1}$. They are D and G bands, respectively, which arise due to $\mathrm{sp}^{2}$ hybridization of carbon atoms. X-ray diffraction patterns confirmed changes in the chemical structure of agar after the incorporation of graphene oxide (Figure 2c). Agar shows two intense $2 \theta$ peaks at $12.56^{\circ}$ and $19.21^{\circ}$ due to its semi-crystalline nature..$^{30} \mathrm{~A}$ slightly intensified peak is observed at $12.56^{\circ}$ along with a slightly broader $2 \theta$ peak at $43.13^{\circ}$. 

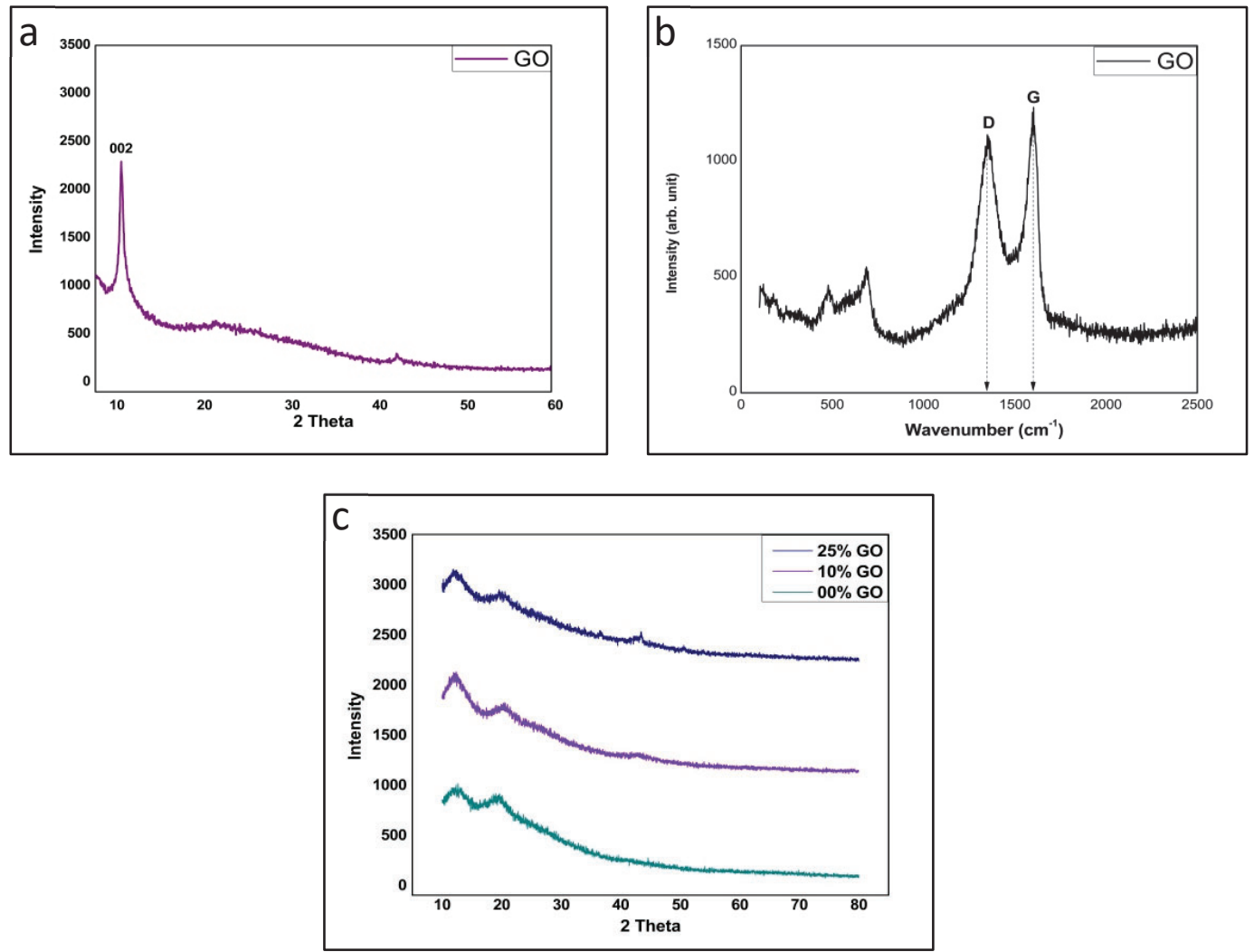

Figure 2. a) XRD pattern of GO b) Raman Spectra of GO c) XRD patterns of Agar@GO composites with varying concentration of GO (GO - graphene oxide).

\section{Optical Properties:}

The synthesized Agar@GO composites were analyzed for optical properties using a UV-visible spectrophotometer. The UVVisible spectrum of the composites was monitored from $200 \mathrm{~nm}$ to $800 \mathrm{~nm}$ by dissolving a certain amount of composites in distilled water. This provided the first confirmation for the formation of Agar@GO composites. Figure 3a depicts the plot of $\%$ Transmittance vs. wavelength $(\mathrm{nm})$. For agar, almost constant transmittance was observed in the visible range, whereas a sudden decrease was observed in the UV range of the spectrum. The sudden decrease in \% Transmittance $(\sim 10 \%)$ is observed in the case of composites and is constant in both UV as well as in the visible region ${ }^{28}$. High $\%$ Transmittance was observed $(\sim 94 \%)$ in the case of agar due to its low concentration. The optical band gap was calculated from UV-visible spectra by Tauc plot method $^{31}$ (Figure 3b). Extrapolating of the straight line in the plot of $(\alpha \mathrm{hv})^{2}$ vs. Energy (hv) gives the value of the optical band gap of composites, which was found to be $3.58 \mathrm{eV}$. Normally lower the value of band gap, the higher is the photocatalytic activity. The observed value (i.e., $3.58 \mathrm{eV}$ ) is sufficiently high and indicates that the energy requirement for excitation of electrons in the composites cannot be fulfilled in the visible region but requires a slightly higher amount of energy (i.e., corresponding to UVVisible region). 

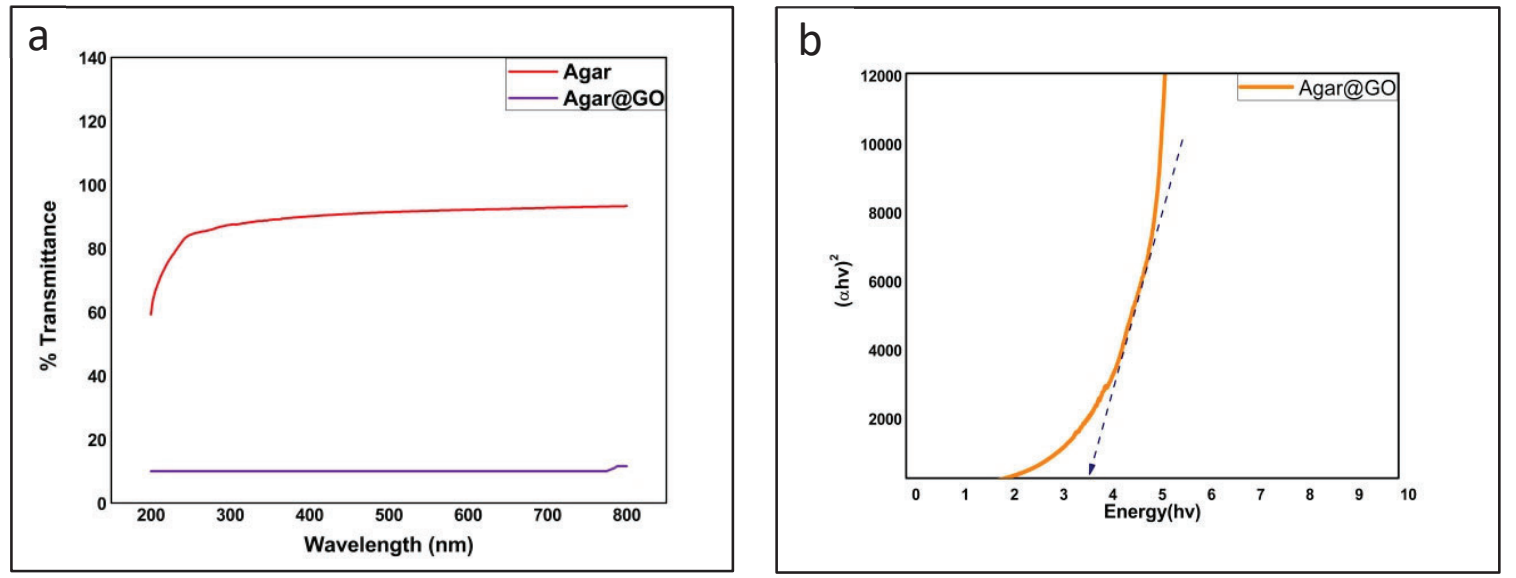

Figure 3. a) \% Transmittance of Agar@GO composites with 25\% (w/w) of GO b) Tauc Plot for Agar@GO composites with 25\% (w/w) of GO (GO graphene oxide).

\section{Photodegradation Experiment:}

The ability of the Agar@GO composites was investigated for the degradation of methylene blue dye under solar irradiation. The degradation was monitored using a UV-visible spectrophotometer. The spectrum showed a gradual decrease in the absorption band at $664 \mathrm{~nm}$ and $292 \mathrm{~nm}$ (Figure 4). Systematic investigation of the effect of reaction parameters on the rate of the reaction was carried out.

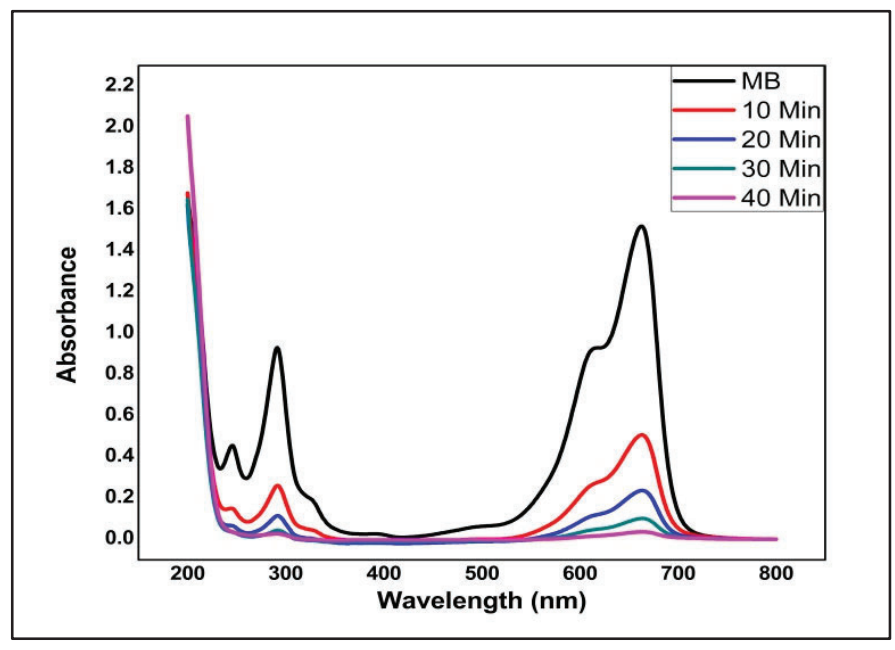

Figure 4. UV-Visible Spectrum of MB Degradation (MB - methylene blue).

\section{Control Experiment:}

Various control experiments were carried out using Agar@GO composites for the degradation of methylene blue under sunlight. The data so obtained from the analysis of the UV-Visible spectrum is depicted in Figure 5. Negligible degradation was observed in the absence of composites and $\mathrm{H}_{2} \mathrm{O}_{2}(\mathrm{MB}+\mathrm{hv})$. A slight increase in percent degradation was observed after the addition of $\mathrm{H}_{2} \mathrm{O}_{2}$ in the presence of light $\left(\mathrm{MB}+\mathrm{H}_{2} \mathrm{O}_{2}+\mathrm{h} v\right)$ and also in the absence of light $\left(\mathrm{MB}+\mathrm{H}_{2} \mathrm{O}_{2}+\right.$ dark $)$. After the addition of Agar@GO composites (MB + $\mathrm{H}_{2} \mathrm{O}_{2}+$ Agar@GO + hv), almost 100\% degradation was observed. The rate constant was also maximized in this case. This indicates that the composites are responsible for driving the reaction at a faster rate. 


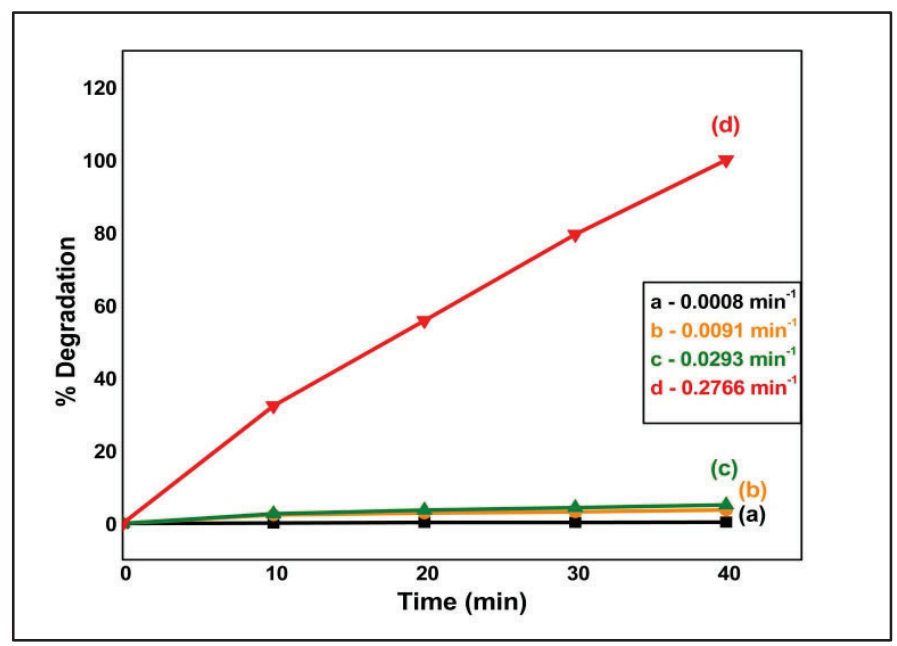

Figure 5. Control Experiment of methylene blue degradation having conditions a) $\mathrm{MB}+\mathrm{h} \nu \mathrm{b}) \mathrm{MB}+\mathrm{H}_{2} \mathrm{O}_{2}+$ dark c) $\mathrm{MB}+\mathrm{H}_{2} \mathrm{O}_{2}+\mathrm{h} \nu$ d) $\mathrm{MB}+\mathrm{H}_{2} \mathrm{O}_{2}+$ Agar@GO + hv (MB - methylene blue).

\section{Kinetics of Reaction:}

Reaction kinetics plays a crucial role in the investigation of reaction systems and their mechanisms. The direction of the reaction can be studied using reaction kinetics. To study the kinetics, the reaction mixtures were analyzed for absorbance band at 664 nm after regular intervals of $10 \mathrm{~min}$ in the range of $200 \mathrm{~nm}$ to $800 \mathrm{~nm}$. A plot of $\ln \left(\mathrm{C}_{\mathrm{t}} / \mathrm{C}_{0}\right)$ vs. Time $(\mathrm{t})$ in min was plotted for each system to obtain the rate constant whose values are given in Table 1 . The rate constant was found to be highest in the presence of $\mathrm{H}_{2} \mathrm{O}_{2}$, Agar@GO, and sunlight. For an optimized system, percent degradation after 10, 20, 30, and 40 min was observed to be $32.34 \%, 55.79 \%, 79.51 \%$, and $99.97 \%$, respectively (Figure 6).

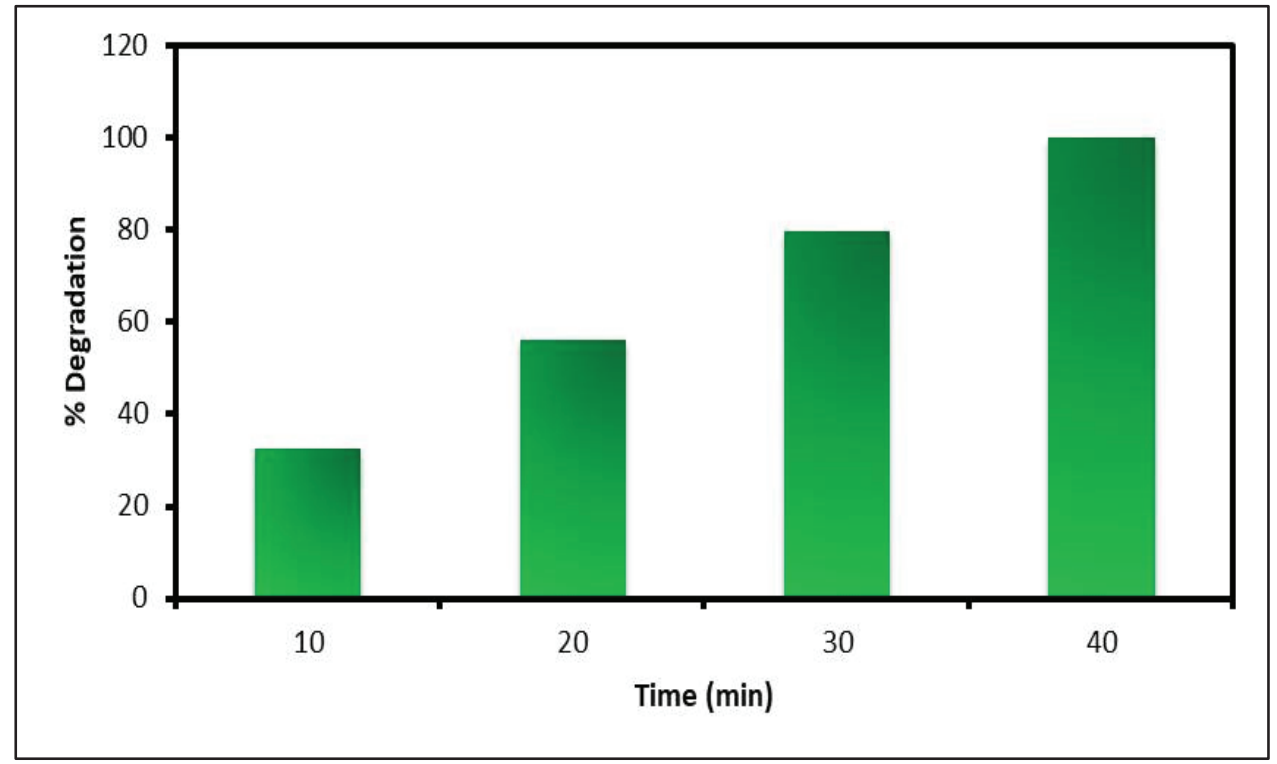

Figure 6. \%Degradation vs. Time (min) for an optimized system. 


\begin{tabular}{|c|c|c|c|c|c|c|c|}
\hline \multicolumn{2}{|c|}{ GO Variation } & \multicolumn{2}{|c|}{ Catalyst Variation } & \multicolumn{2}{|c|}{ Dye Concentration } & \multicolumn{2}{|c|}{$\mathrm{H}_{2} \mathrm{O}_{2}$ Variation } \\
\hline$\%(w / w)$ & $\mathrm{k}\left(\min ^{-1}\right)$ & $\begin{array}{l}\text { Amount } \\
\text { (mg) }\end{array}$ & $\mathrm{k}\left(\min ^{-1}\right)$ & $\begin{array}{c}\text { MB } \\
\text { (ppm) }\end{array}$ & $\mathrm{k}\left(\min ^{-1}\right)$ & $\begin{array}{c}\mathrm{H}_{2} \mathrm{O}_{2} \\
(\mathrm{ml})\end{array}$ & $\mathrm{k}\left(\min ^{-1}\right)$ \\
\hline 5 & 0.0560 & 1.0 & 0.0965 & 20 & 0.2765 & 0.05 & 0.1245 \\
\hline 10 & 0.1256 & 2.0 & 0.1265 & 40 & 0.2015 & 0.10 & 0.1658 \\
\hline 20 & 0.1765 & 5.0 & 0.1725 & 60 & 0.1568 & 0.15 & 0.2158 \\
\hline 25 & 0.2791 & 10.0 & 0.2695 & 80 & 0.9574 & 0.20 & 0.2766 \\
\hline - & - & - & - & 100 & 0.0869 & - & - \\
\hline
\end{tabular}

Table 1. Variation of rate constant with change in reaction parameters.

III. Effect of reaction parameters on rate of reaction:

Reaction parameters such as the amount of catalyst, the concentration of $\mathrm{H}_{2} \mathrm{O}_{2}$, etc., play a vital role in determining the rate of degradation of organic dyes under solar irradiation. In the present study, the effects of such parameters were studied systematically.

a. Concentration of GO:

Due to the large surface area of graphene oxide, a slight change in amount can greatly influence the rate of degradation. The systematic study of the effect of graphene oxide dosage (vi\%. $5 \%, 10 \%, 20 \%$, and $25 \% \mathrm{w} / \mathrm{w}$ ) on the degradation of methylene blue shows that a larger amount of graphene oxide drives the reaction at a faster rate (Figure 7a). When the reaction was carried out with composites containing 25\% graphene oxide (w/w), the rate constant of the reaction was highest, and the plot for \%degradation vs. Time (min) exhibited an almost linear nature. Thus, $25 \%$ graphene oxide (w/w) was optimized and was used for further experiments.

b. Concentration of Agar@GO Composites:

The degradation of organic dyes is greatly influenced by the amount of catalyst. ${ }^{32}$ To make the process more practical and costeffective, the minimization of catalyst concentration is of utmost importance. The influence of the amount of catalyst (1.0 mg, 2.0 $\mathrm{mg}, 5.0 \mathrm{mg}, 10.0 \mathrm{mg})$ on the degradation of $50.00 \mathrm{ml}$ methylene blue dye $(20 \mathrm{ppm})$ at $\mathrm{H}_{2} \mathrm{O}_{2}-0.20 \mathrm{ml}$ and initial $\mathrm{pH}(\mathrm{pH}=8.4)$ is shown in Figure 7b. $10 \mathrm{mg}$ of composites were found to be more effective in driving the reaction at a faster rate as the rate constant was maximum in this case compared to others. A gradual decrease in rate constant was observed with a decrease in the concentration of composites. All further experiments were carried out at $10.0 \mathrm{mg}$ of Agar@GO composites.

c. Concentration of $\mathrm{H}_{2} \mathrm{O}_{2}$ :

To make the reaction economically feasible, the optimization of $\mathrm{H}_{2} \mathrm{O}_{2}$ is very important. Variation of $\mathrm{H}_{2} \mathrm{O}_{2}$ concentration and its effect on the rate of degradation was monitored, and the data so obtained is shown in Figure 7c. An increase in the rate of reaction was observed with the increase in the concentration of $\mathrm{H}_{2} \mathrm{O}_{2}$. Kinetics studies showed an increase in the rate constant with increasing concentration of $\mathrm{H}_{2} \mathrm{O}_{2}$. The rate was observed to be faster, with $0.20 \mathrm{ml}$ of $\mathrm{H}_{2} \mathrm{O}_{2}$ having a rate constant of 0.2695 $\mathrm{min}^{-1}$. Hence further experiments were carried out at $0.20 \mathrm{ml}$ of $\mathrm{H}_{2} \mathrm{O}_{2}$.

\section{d. Concentration of methylene blue:}

Another parameter that greatly influences the reaction rate is dye concentration. Degradation of methylene blue was studied at various dye concentrations viæ. 20 ppm, 40 ppm, 60 ppm, 80 ppm, and 100 ppm by keeping rest parameters constant (Agar@GO - $10 \mathrm{mg} ; \mathrm{H}_{2} \mathrm{O}_{2}-0.2 \mathrm{ml}$; pH - 8.4). From Figure 7d, it can be seen that, as the concentration of dye increases, the rate of degradation decreases. The rate constant was observed to be highest at a dye concentration of $20 \mathrm{ppm}$. 

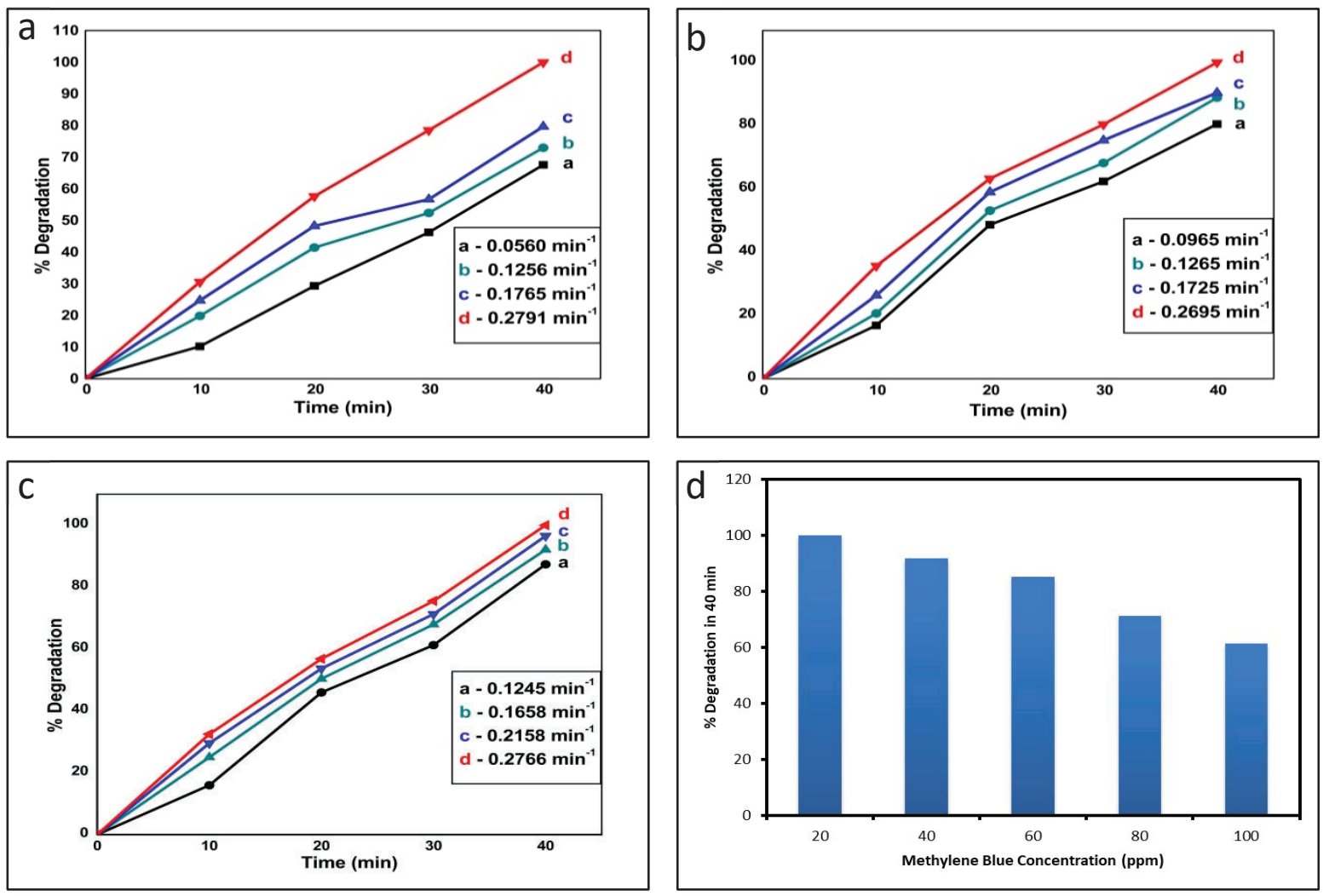

Figure 7. a) Variation of graphene oxide (w/w) with conditions: $a-5 \%$; b - 10\%; $\mathrm{c}-20 \%$; $-25 \%$ b) Variation of Agar@GO with conditions: a - 1.0 mg; b $2.0 \mathrm{mg} ; \mathrm{c}-5.0 \mathrm{mg} ; \mathrm{d}-10.0 \mathrm{mg}$ c) Variation of $\mathrm{H}_{2} \mathrm{O}_{2}$ with conditions: a $-0.05 \mathrm{ml}$; b $-0.10 \mathrm{ml}$; c $-0.15 \mathrm{ml} ; \mathrm{d}-0.20 \mathrm{ml}$. d) Effect of variation in dye concentration on rate of degradation

\section{Plausible Mechanism of Photo Degradation:}

Agar shows remarkable properties after forming composites with graphene oxide. The lower band gap is one of those remarkable properties which allow these composites to be used for photodegradation of organic dyes. There is no exact mechanism known till date for degradation of organic dyes using Agar@GO composites under solar irradiation. To the best of our knowledge, it is the first report in which the possible mechanism for the degradation of methylene blue is reported using the Agar@GO composites (Figure 8).

When Agar@GO composites are added to the aqueous solution of methylene blue, the molecules of organic dye get adsorbed $\left(\mathrm{MB}^{*}\right)$ on the surface of the agar. Agarose and agaropectin, the two components of agar, contain -OH groups with which the dye molecules interact and get adsorbed. As per the literature survey, methylene blue dye gets adsorbed on agar in the form of monolayers and is irrespective of the concentration of dye. This is due to the presence of a large number of 3, 6-anhydro-Lgalactopyranose units. ${ }^{33}$

$\mathrm{MB}+$ Agar $\rightarrow \mathrm{MB}^{*}+$ Agar

Equation 1.

After irradiating the solution containing Agar@GO composites with visible light, graphene oxide (GO), the key component of Agar@GO composites, releases a pair of holes and electrons. ${ }^{34}$

$\mathrm{GO} \rightarrow \mathrm{e}^{-}+$holes

\section{Equation 2.}

The band gap of graphene oxide $(\sim 3.5 \mathrm{eV})$ allows this generation of pairs on its surface. This photo inductively generated electron-hole pairs then react with the $\mathrm{H}_{2} \mathrm{O}$ and $\mathrm{O}_{2}$ to form active oxygen species.

holes $+\mathrm{H}_{2} \mathrm{O} \rightarrow \mathrm{H}^{+}+\mathrm{OH} \bullet$

Equation 3.

$\mathrm{e}^{-}+\mathrm{O}_{2} \rightarrow \mathrm{O}_{2}^{\bullet-}$

Equation 4. 
$\mathrm{O}_{2} \bullet^{-}+\mathrm{H}^{+} \rightarrow \mathrm{HO}_{2} \bullet$

Equation 5.

The superoxide ion and hydroxyl free radicals generated from the above reaction react with organic dye and forms the degradation products, which are $\mathrm{CO}_{2}$ and $\mathrm{H}_{2} \mathrm{O} .{ }^{35}$

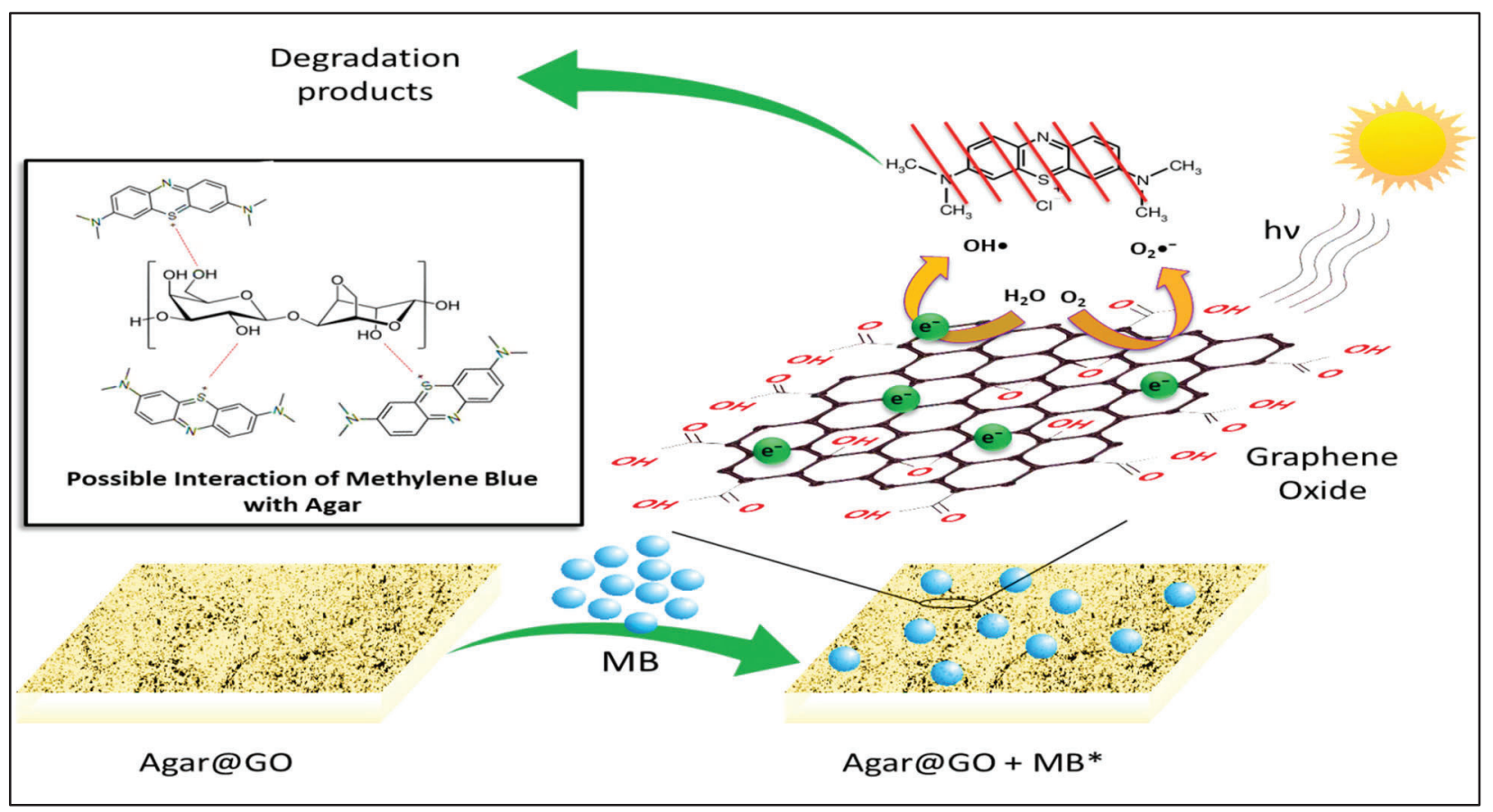

Figure 8. Plausible Mechanism of Photo Degradation of methylene blue dye using Agar@GO composites.

\section{DISCUSSION}

The characteristic peak obtained at around $2 \theta=10^{\circ}$ confirms the formation of graphene oxide. The peak corresponds to the 002 plane and arises due to the increase in interatomic layers, which is associated with the addition of reactive oxygenated groups. The small hump at $2 \theta=43.1^{\circ}$ can be attributed to a turbostratic disorder. ${ }^{36}$ Significant disorder in the as synthesized graphene oxide was shown by the Raman spectra. The two intense peaks, namely D and G, indicate structural disorder in graphene oxide. The D peak, which is generally referred to as disorder band at $1349 \mathrm{~cm}^{-1}$, represents the breathing mode of aromatic rings. ${ }^{37}$ The presence of two additional peaks, namely $2 \mathrm{D}$ and $\mathrm{D}+\mathrm{G}$, also indicated disorderedness in graphene oxide. The results obtained from XRD patterns and Raman spectra for graphene oxide were in excellent agreement with results reported in the literature and thus confirmed its formation. ${ }^{37}$

The analysis of synthesized composites shows structural changes after the incorporation of graphene oxide into the agar. X-ray diffraction patterns of composites reveal that, as the amount of graphene oxide increases, the intensity of the $2 \theta$ peak at $43.13^{\circ}$ increases. A sudden decrease in the $\%$ Transmittance of composites compared to agar is associated with the presence of phenolic groups of graphene oxide. ${ }^{38}$ Agar does not exhibit photo-induced activity, whereas the composites showed active photo nature. It is due to the lower band gap value of $3.58 \mathrm{eV}$ that lies in the photoactive range. All the above observations support the structural changes in the properties of agar are due to the incorporation of graphene oxide.

The UV-visible spectrum recorded for degradation of methylene blue dye shows a decrease in absorbance bands at two wavelengths, $664 \mathrm{~nm}$, and $292 \mathrm{~nm}$, respectively. The decrease in the absorbance band at $664 \mathrm{~nm}$ corresponds to the degradation of chromophores of the dye, whereas a decrease in the band at $292 \mathrm{~nm}$ is attributed to the degradation of organic rings of the dye. ${ }^{39}$ The degradation of organic rings leads to the conversion of harmful dye into less harmful organics such as water and $\mathrm{CO}_{2}$.

The systematic study of influencing factors for rate of reaction shows that the rate of reaction is proportional to the amount of graphene oxide loaded into agar, amount of composites used, and amount of $\mathrm{H}_{2} \mathrm{O}_{2}$, whereas it exhibits inverse relation with the concentration of dye used for degradation. The coefficient of determination factor $\left(\mathrm{R}^{2}\right)$ obtained from the first-order kinetic 
model for an optimized system is $0.994 .^{25}$ The closeness of the $\mathrm{R}^{2}$ value to unity indicates that the data fit the linear model in an excellent agreement and follows pseudo-first-order kinetics.

\section{CONCLUSION}

The synthesized and characterized Agar@GO composites with various weight ratios of graphene oxide showed excellent photocatalytic activity for the degradation of methylene blue dye. All the reactions were carried without 30 minutes of adsorption in the dark and thereby reducing the cost and time of degradation. The relatively high biodegradability and lower band gap could allow the composites to be used as a photo-catalyst for various reactions. Along with excellent photocatalytic activity, the composites could find potential applications in the manufacturing of biocompatible materials like bio-polymers, which could replace polythene based plastic materials.

\section{ACKNOWLEDGEMENTS}

The authors are thankful to Dr. Nilesh Kulkarni from TIFR, Mumbai, for providing XRD data, the Savitribai Phule University of Pune for Raman Spectra. The authors are thankful to Dr. K. G. Bhole and Dr. Suresh Kadam (HOD Physics) K. E. T's, Vinayak Ganesh Vaze College (Autonomous), Mulund, Mumbai, for scientific discussion.

\section{REFERENCES}

1. Lellis, B., Fávaro-Polonio, C.Z., Pamphile, J.A., Polonio, J.C. (2019) Effects of textile dyes on health and the environment and bioremediation potential of living organisms, Biotechnology Research and Innovation 3, 275-290. https://doi.org/10.1016/j.biori.2019.09.001.

2. Berradi, M., Hsissou, R., Khudhair, M., Assouag, M., Omar, C., El Bachiri, A., El Harfi, A. (2019) Textile finishing dyes and their impact on aquatic environs, Heliyon 5, e02711. https://doi.org/10.1016/j.heliyon.2019.e02711.

3. Houas, A., Lachheb, H., Ksibi, M., Elaloui, E., Guillard, C., Herrmann, J-M. (2001) Photocatalytic degradation pathway of methylene blue in water, Applied Catalysis B: Environmental 31, 145-157. https:// doi.org/ 10.1016/S0926-3373(00)00276-9.

4. Gadallah, M.A.A. (1996) Phytotoxic effects of industrial and sewage waste waters on growth, chlorophyll content, transpiration rate and relative water content of potted sunflower plants, Water Air Soil Pollut 89, 33-47. https://doi.org/10.1007/BF00300420.

5. Chala, S., Wetchakun, K., Phanichphant, S., Inceesungvorn, B., Wetchakun, N. (2014) Enhanced visible-light-response photocatalytic degradation of methylene blue on Fe-loaded BiVO4 photo-catalyst, Journal of Alloys and Compounds 597, $129-135$. https:// doi.org/10.1016/j.jallcom.2014.01.130.

6. Shannon, M., Bohn, P., Elimelech, M., Georgiadis, J., Mariñas, B., Mayes, A., (2008) Science and technology for water purification in the coming decades, Nature 452, 301-310. https:/ / doi.org/ 10.1038/ nature06599.

7. Soboleva, N.M., Nosovich, A.A., Goncharuk, V.V. (2007) The heterogenic photocatalysis in water treatment processes, J. Water Chem. Technol. 29, 72-89. https://doi.org/10.3103/S1063455X07020038.

8. Pourahmada A., Sohrabnezhad Sh., Kashefian. E. (2010) AgBr/nanoAlMCM-41 visible light photo-catalyst for degradation of methylene blue dye, Spectrochimica Acta Part A 77, 1108-1114. https:// doi.org/10.1016/j.saa.2010.09.006.

9. Rajput, R.S., Pandey, S., Bhadauria, S., (2017) Status of water pollution in relation to industrialization in Rajasthan, Rev Environ Health 32, 245-252. https:// doi.org/10.1515/ reveh-2016-0069.

10. Vidal, O. (2018) 1 - Framework and Challenges, Mineral Resources and Energy, 1-10. https://doi.org/10.1016/B978-1-78548267-0.50001-2.

11. O'Connor, I.A., Golsteijn, L., Hendriks A.J. (2016) Review of the partitioning of chemicals into different plastics: Consequences for the risk assessment of marine plastic debris, Marine Pollution Bulletin 113, 17-24. bttps://doi.org/10.1016/j.marpolbul.2016.07.021.

12. Liu J., Wang Z., Liu L., Chen W. (2011) Reduced graphene oxide as capturer of dyes and electrons during photocatalysis: surface wrapping and capture promoted efficiency, Phys Chem Chem Phys 29, 13216-13221. bttps://doi.org/10.1039/c1cp20504h.

13. Liu, T., Li, Y., Du, Q., Sun, J., Jiao, Y., Yang, G., Wang, Z., Xia, Y., Zhang, W., Wang, K., Zhu, H., Wu, D. (2012) Adsorption of methylene blue from aqueous solution by graphene, Colloids and Surfaces B: Biointerfaces 90, 197-203. bttps:// doi.org/10.1016/j.colsurfb.2011.10.019.

14. Liu, Y., Liu, C., Liu, Y., (2011) Investigation on fluorescence quenching of dyes by graphite oxide and graphene, Applied Surface Science 257, 5513-5518. https:// doi.org/ 10.1016/j.apsusc.2010.12.136.

15. Ramesha, G.K., Kumara, A.V., Muralidhara, H.B., Sampath, S. (2011) Graphene and graphene oxide as effective adsorbents toward anionic and cationic dyes, J Colloid Interface Sci 361, 270-277. https://doi.org/10.1016/j.jcis.2011.05.050.

16. Smith, A.T., LaChance, A.M., Zeng, S., Liu, B., Sun, L. (2019) Synthesis, properties, and applications of graphene oxide/reduced graphene oxide and their nanocomposites, Nano Materials Science 1, 31-47. bttps:// doi.org/10.1016/j.nanoms.2019.02.004.

17. Paredes, J. I., Villar-Rodil, S., Martínez-Alonso, A., Tascón, J. M. D. (2008) Graphene Oxide Dispersions in Organic Solvents, Langmuir 24, 10560-10564. https:// doi.org/10.1021/la801744a. 
18. Chen, S., Zhu, J., Wu, X., Han, Q., Wang, X. (2010) Graphene oxide-MnO2 nanocomposites for supercapacitors, ACS Nano 4, 2822-2830. bttps://doi.org/10.1021/nn901311t.

19. Li, Z.J., Yang, B.C., Zhang, S.R., Zhao, C.M. (2012) Graphene oxide with improved electrical conductivity for super capacitor electrodes, Applied Surface Science 258, 3726-3731. bttps:// doi.org/10.1016/j.apsusc.2011.12.015.

20. Piao, Y., Chen, B. (2016) One-pot synthesis and characterization of reduced graphene oxide-gelatin nanocomposite hydrogels, RSC Adv 6, 6171-6181. https://doi.org/10.1039/C5RA20674J.

21. Freile-Pelegrín, Y., Madera-Santana, T., Robledo, D., Veleva, L., Quintana, P., Azamar, J.A. (2007) Degradation of agar films in a humid tropical climate: Thermal, mechanical, morphological and structural changes, Polymer Degradation and Stability 92 , 244-252. https://doi.org/10.1016/j.polymdegradstab.2006.11.005.

22. Mesbah, N.M., Wiegel, J., (2006) 19 Isolation, Cultivation and Characterization of Alkalithermophiles, Methods in Microbiology 35, 451-468. https:/ / doi.org/10.1016/S0580-9517(08)70022-9.

23. Azim, M.B., Tanima, I.A., Rezaula, R.M., Tareqa, R., Rahula, A.H., Kurnyb A.S.W., Gulshanb, F. (2018) Degradation of methylene blue using graphene oxide-tin oxide nanocomposite as photo-catalyst, arXiv: Materials Science, 202-209, Paper ID: C117.

24. Seema, H., Kemp, K.C., Chandra, V., Kim, K.S. (2012) Graphene-SnO2 composites for highly efficient photocatalytic degradation of methylene blue under sunlight, Nanotechnology 23, 355705. https:// doi.org/ 10.1088/0957-4484/23/35/355705.

25. Chen, L., Li, Y., Du, Q., Wang, Z., Xia, Y., Yedinak, E., Lou, J., Ci, L. (2017) High performance agar/graphene oxide composite aerogel for methylene blue removal, Carbohydrate Polymers 155, 345-353. bttps:// doi.org/ 10.1016/j.carbpol.2016.08.047.

26. Ionita, M., Crica, L.E., Tiainen, H., Haugen, H.J., Vasile, E., Dinescu, S., Costache, M., Iovu, H. (2015) Gelatin-Poly (vinyl alcohol) Porous Biocomposites Reinforced with Graphene Oxide as Biomaterials, J. Mater, Chem. B 4, $282-291$. bttps:// doi.org/10.1039/C5TB02132D.

27. Belay, M., Nagarale, R.K., Verma, V. (2017) Preparation and characterization of graphene-agar and graphene oxide-agar composites, Journal of Applied Polymer Science 134, 45085. https:/ / doi.org/10.1002/ APP.45085.

28. Hummers, W. S.; Offeman, R. E. (1958) Preparation of Graphitic Oxide, J. Am. Chem. Soc. 80, 1339-1339. https://doi.org/10.1021/ja01539a017.

29. Gascho, J.L.S., Costa, S.F., Recco, A.A.C., Pezzin, S.H. (2019) Graphene Oxide Films Obtained by Vacuum Filtration: X-Ray Diffraction Evidence of Crystalline Reorganization, Journal of Nanomaterials 2019, 1-12. https:// doi.org/10.1155/2019/5963148.

30. Kanmani, P., Rhim, J.W. (2014) Antimicrobial and physical-mechanical properties of agar-based films incorporated with grapefruit seed extract, Carbohydrate Polymers 102, 708-716. https:// doi.org/ 10.1016/j.carbpol.2013.10.099.

31. Debanath, M.K., Karmakar, S. (2013) Study of blueshift of optical band gap in zinc oxide (ZnO) nanoparticles prepared by low-temperature wet chemical method, Materials Letters 111, 116-119. bttps:/ / doi.org/10.1016/j.matlet.2013.08.069.

32. Jangam, K., Patil, K., Balgude, S., Patange, S., More, P. (2021) Synthesis and characterization of magnetically separable Zn1xCoxFeMnO4 nanoferrites as highly efficient photo-catalyst for degradation of dye under solar light irradiation, Journal of Physics and Chemistry of Solids 148, 109700. https:/ / doi.org/10.1016/j.jpcs.2020.109700.

33. Samiey, B., Ashoori, F. (2012) Adsorptive removal of methylene blue by agar: effects of $\mathrm{NaCl}$ and ethanol, Chemistry Central Journal 06, 14. https:/ / doi.org/ 10.1186/1752-153X-6-14.

34. Krishnamoorthy, K., Mohan, R., Kim, S.-J. (2011) Graphene oxide as a photocatalytic material, Applied physics letters 98 , 244101. https://doi.org/10.1063/1.3599453.

35. Jangam, K., Patil, K., Balgude, S., Patange, S., More, P. (2020) Magnetically separable Zn1-xCo0.5xMg0.5xFe2O4 ferrites: stable and efficient sunlight-driven photocatalyst for environmental remediation, RSC Adv. 10, 42766-42776. bttps:/ / doi.org/10.1039/DORA08172H.

36. Emiru, T.F., Ayele D.W. (2017) Controlled synthesis, characterization and reduction of graphene oxide: A convenient method for large scale production, Egyptian Journal of Basic and Applied Sciences 04, 74-79. bttps:/ / doi.org/10.1016/j.ejbas.2016.11.002.

37. Shahriary, L., Athawale, A. (2014) Graphene Oxide Synthesized by using Modified Hummers Approach, International Journal of Renewable Energy and Environmental Engineering 02, 58-63.

38. Ganguly, A., Sharma, S., Papakonstantinou, P., Hamilton, J. (2011) Probing the thermal deoxygenation of graphene oxide using high-resolution in situ X-ray-Based spectroscopies, J. Phys. Chem. C 115, 17009-17019. https://doi.org/10.1021/jp203741y.

39. Rauf, M.A., Meetani, M.A., Khaleel, A., Ahmed, A. (2010) Photocatalytic degradation of Methylene Blue using a mixed catalyst and product analysis by LC/MS, Chemical Engineering Journal 157, 373-378. https:/ / doi.org/ 10.1016/j.cej.2009.11.017.

\section{ABOUT STUDENT AUTHORS}

Shreyas Dindorkar is an undergraduate student at K. E. T.'s V. G. Vaze College (Autonomous), Mulund (E) majoring in chemistry. After completing his Bachelor's degree in April 2021, his objective is to seek an R\&D chemist position in quantum materials and theoretical chemistry.

Jaymin Mistry is an undergraduate student at K. E. T.'s V. G. Vaze College (Autonomous), Mulund (E). He will graduate in April 2021 with a Bachelor's degree. He aims to pursue higher studies in data science. 
Jayesh Hire is an undergraduate student at K. E. T.'s V. G. Vaze College (Autonomous), Mulund (E). He will complete his Bachelor's degree in April 2021 with physics as majors and aims to become an innovative researcher in the field of optics.

Khushi Jain is an undergraduate Biotechnology student at K. E. T.'s V. G. Vaze College (Autonomous), Mulund (E). She will graduate with a B.S. degree in April 2021 with an objective of high-quality research in the field of cancer biotechnology and environmental wellbeing through an interdisciplinary approach.

Nandini Khona is an undergraduate Biotechnology student at K. E. T.'s V. G. Vaze College (Autonomous), Mulund (E). After getting a B.S. degree in April 2021, she plans to pursue higher studies in the field of biotechnology.

Shreya Peddakolmi is an undergraduate Biotechnology student at K. E. T.'s V. G. Vaze College (Autonomous), Mulund (E), and will complete her B.S. degree in April 2021. She is planning for higher studies and research in the field of animal biotechnology.

\section{PRESS SUMMARY}

Colorants used in textile industries are organic dyes that affect the quality of water and have been recognized as the root of pollution over the last few years. The current study presents the investigation of structural and optical properties of biocompatible Agar@GO composites and their photocatalytic activity in the degradation of organic dyes. The synthesis was carried out by mixing the agar solution and dispersion of graphene oxide in the desired ratio. The critically analyzed results show that the reaction follows the pseudo first order. Only $10.0 \mathrm{mg}$ of synthesized composites were found to show an excellent activity for degradation of methylene blue dye and thus increasing the economic viability of the reaction. Within a short period of 40 minutes, $100 \%$ degradation was observed. 